\title{
A Critical Analysis of Risk Management Knowledge within the Sedibeng District Municipality, South Africa
}

\author{
Meyer, N. \\ North-West University, Faculty of Economic Sciences and Information Technology \\ PO Box 1174, Vanderbijlpark \\ Email: natanya.meyer@nwu.ac.za
}

\section{Doi:10.5901/mjss.2014.v5n7p163}

\begin{abstract}
Since the introduction of the Public Finance Management Act (PFMA) in 1999, the Municipal Finance Management Act (MFMA) in 2003 and the Public Sector Risk Management Framework (PSRMF) in 2010, municipalities had to start focusing on more efficient risk management as part of operational activities. Information for the study was obtained from two groups of officials employed at the Sedibeng District Municipality in southern Gauteng, South Africa, by means of one-on-one interviews and questionnaires. Group 1 consisted of 14 officials, not in management positions, and Group 2 of 11 employees in senior management. The questionnaire comprised five sections aimed at determining the knowledge and attitude of the respondents regarding risk management. Responses clearly indicated that knowledge of risk management differed substantially between Group 1 and Group 2. The knowledge, monitoring, assessment, identification and response to risk management activities were minimal or unclear to those not in management positions. Participants in management positions, in contrast, were more aware of risk management responsibilities; although, they admitted that the responsibilities were not always fulfilled as required, and in many cases only to comply with regulations. This paper proposes various recommendations that could improve the overall management and sustainability of risk management within the Sedibeng municipality in particular and other municipalities in general.
\end{abstract}

Keywords: Risk Management, Financial Management, Sedibeng District Municipality, Public Sector Risk Management Framework, South Africa

\section{Introduction}

Risk is an inevitable and unavoidable part of life and, if not properly managed, can lead to substantial financial losses. The word risk is derived from the Italian word riscare, which means, "to dare" (Garret 2003:194). Garret (2013:194) opines that risk is concerned with real or possible events that can prevent an organisation from achieving its objectives and goals. Risk management is an important function within private and public enterprises. According to Van Niekerk (2012:66), municipalities must address challenges and constraints in order to improve financial management and risk management, as well as internal control responsibilities. Without effective planning and risk assessment procedures in place, serious losses could occur within a municipality. Research on risk management within local government is limited, and is desirable not only to improve its adoption but also to determine to what extent it is being applied in this context. Management should be responsible, not only to identify risks, but also to ensure sufficient and effective plans of action regarding assessment and monitoring of the identified risks are in place (Turnbull Report 2005). Organisations once dealt mostly with financial risk; whereas, more recently a much broader risk framework has been identified. Rossouw and Van Vuuren (2010:218) aver that all risks could eventually have financial implications for the organisation.

In the 2012/13 Management Performance Assessment Tool (MPAT) of national and provincial departments, Chabane stated, "there have been improvements in the management standards related to strategic management and financial management"; however, "more needs to be done by departments to improve levels of management practices." According to the 2011/12 MPAT, risk management falls under the section of governance and accountability within the management performance areas, and can be considered a management function (The Presidency 2012).

Risk is defined as exposure to a potential hazard occurring, or the possibility of an undesirable outcome that may result from a given action. Within the discipline of financial management, the term indicates an expectation that the actual outcome of a project may differ from the expected result. The magnitude of the possible difference between these consequences reflects the size of the risk (Correia et al. 2003:3).

The term risk management can be explained as involving the identification, prioritisation and assessment of a risk, 
or various risks. It addresses the effect of certainty or uncertainty on situations, which could be positive or negative. It can further be elaborated upon as maximising the allocation of scarce resources in a co-ordinated and economical way. This is done by monitoring and controlling the probability of events arising, for maximum profit or opportunities (Crockford 1986:1-18). According to Spaulding (2005:1), the term can further be analysed as the control, analysis and avoidance minimising, or the elimination of outcomes that are unacceptable, by using advanced techniques such as risk assumption, retention, avoidance, transfer, or any other strategy or combination of strategies, in the effective management of current and future events.

The concepts of financial management and risk management have shared outcomes, which are the reduction of risk, increased profits and improved use of resources. The expression 'managing risk' involves elements of uncertainty because it requires the responsible manager to anticipate the future (Cleary \& Malleret, 2006:74).

Since the implementation of the South African Constitution in 1996, municipalities have been allocated significantly more functions and responsibilities than before (South Africa 1996). Consequently, there is increased pressure on financial responsibilities, resulting in increased exposure to risk. In order for municipalities to perform their constitutional duties, more and better resources are required. Resources take the form of management, labour, planning and, most importantly, finances (Cameron 1999:250).

Many challenges have been identified within local municipalities in South Africa; in particular, the need for improved management of financial resources at all levels of government. Kenosi (2007:112) points out that sound financial management can be related directly to proper risk management procedures and thus forms an integral part of the management process in local government.

Risk management has become a common practice in many private companies. Since the introduction of the Public Finance Management Act (1 of 1999) (PFMA) and the Municipal Finance Management Act (56 of 2003) (MFMA), it has also assumed an important role in public administration. Sections 38(1)(a)(i) and 51(1)(a)(i) of the PFMA, and sections 62(1)(c)(i) and 95(c)(i) of the MFMA require accounting officers to ensure that an effective, transparent and efficient risk management system is in place. Visser and Erasmus (2009:199) assert the importance for all institutions, whether private or public, to apply basic risk management principles within their central management operations. Furthermore, risk management is seen now, not so much about solving a problem, as it is about preventing the problem from occurring.

It is important to distinguish the difference between strategic and operational risk. According to Frigo and Anderson (2011:21-22, 61), part of strategic risk management involves the management of a municipality to predict and manage risk in highly uncertain environments and situations. The following six principles form the basis of strategic risk:

- identifying, assessing and managing internal and external risks;

- creating and protecting value to customers;

- strategic risk management is a primary component of enterprise risk management;

- it can be affected by the management of the municipality as it is part of enterprise risk management;

- there should be a clear strategic view on how the municipality will assess scenarios in order to achieve its objectives; and

- it must always be seen as a continuous process of reviewing and monitoring risks by means of strategy execution and management (Frigo \& Anderson 2011:21-22, 61).

Operational risks can be defined as those risks relating to an organisation's internal activities. It can be defined further as risks relating to or arising from systems, processes and people, such as legal risk, fraud and environmental issues (Jobst 2007:10-15). Operational risk analysis is more difficult than other risk analysis processes because a large number of elements or sources are working together. A way to overcome this is by grouping the risks in order of probability and likely impact or consequence (Weller 2008:35).

\subsection{Risk Management within the Public Sector}

The statutory framework for public financial management includes many legislated policies that have a direct bearing on the way in which financial management is dealt with in the different spheres of government. Legislation that refers to risk management and to financial management includes the MFMA, PFMA and the Public Sector Risk Management Framework (PSRMF).

\subsection{Public Finance Management Act (1 of 1999)}

The purpose of the PFMA includes regulating financial management in the national government and provincial 
governments, ensuring that all revenue, expenditure, assets and liabilities of government are managed efficiently and effectively, and providing for the responsibilities of persons entrusted with financial management in government (South Africa 1999).

\subsection{The Municipal Finance Management Act (56 of 2003)}

The primary objective of the MFMA is to secure sound and sustainable management of the financial affairs of the three spheres of government, and to lead such policies and reforms. The main aim of this is to improve delivery of services to the population as a whole (South Africa 2003).

Risk management is referred to in various sections of the MFMA and some of the extracts include:

- "that the municipality has and maintains effective, efficient and transparent systems of financial and risk management and internal control" (South Africa 2003:74);

- "the internal audit unit of a municipality or municipal entity must prepare a risk-based audit plan and an internal audit plan and matters relating to risk and risk management" (South Africa 2003:152); and

- "the audit committee should advise the municipality on matters relating to risk management" (South Africa 2003:154).

\subsection{Public Sector Risk Management Framework (PSRMF)}

The National Treasury introduced the PSRMF in 2010 with the main purpose to maintain transparent risk management systems that are efficient and effective. It was created in coordination with the PFMA and the MFMA for institutions to maintain efficient and transparent systems of risk management (South Africa 2010:1-40).

\subsection{The risk management process}

Risk management can take place in various ways. The following describes eight elements or objectives of the risk management strategy:

- controlled environment - to create an environment that is facilitating, supportive and conducive for the practice of effective risk management;

- objective setting - objectives should be in line with the mission and vision of the municipality;

- risk identification - events should be identified that can result in objectives not being achieved in the most efficient and economic way;

- risk assessment - risks must be assessed in terms of impact and likelihood in order to determine the specific priority of the risk;

- risk response - department should determine how they will respond to the risks;

- communication and information - proper communication and information access must be provided to employees to perform risk management effectively;

- control activities - implement control activities in line with risk response plan; and

- monitoring - specific risk management must be monitored by the relevant managers as well as the whole system at risk (Umdoni Local Municipality 2011:64). 
Figure 1: Schematic illustration of the principal elements involved in risk management

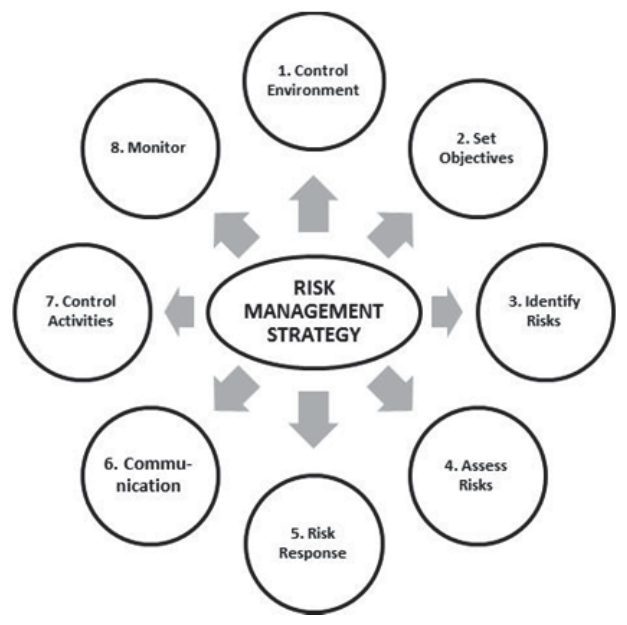

Source: Adapted from Umdoni Local Municipality (2011:64)

These eight objectives incorporated within the PSRMF served as the basis of the design of the questionnaire used in this study.

\section{Methodology and Research Process}

In the 2011/2012 audit report, Sedibeng District Municipality (SDM) received an unqualified audit report, but with findings from the South African Auditor General, and this has been the case for the seventh successive year (Manuli 2012, AGSA 2012). An unqualified report with findings means that financial statements are free from material misstatements, and can be considered financially trustworthy; however, the audit report did contain material findings concerning other areas of non-compliance (The Local Government Handbook 2013). One of the findings listed in the 2011 report was that there was a lack of appropriate risk management such as continuous risk assessment and monitoring (AGSA 2011:1-5). Not assessing and monitoring risks on a continuous basis could lead to financial losses. This was one of the reasons for choosing SDM for this specific study.

The study was conducted early in 2013, and as part of the initial study, a status quo analysis of SDM regarding risk support was determined. It was found that sufficient policies and supporting documents were in place within the municipality. Some of these documents included an up-to-date Enterprise Risk Management Framework, insurance risk assessments, and a risk assessment handbook. From the analysis of these documents, the conclusion can be made that sufficient theoretical documentation exists, including step-by-step instructions on how risk should be managed. These documents also take into account the guidelines as set out in the PSRMF.

Two groups of employees were identified within the SDM, a category C municipality (district municipality with a primary responsibility to undertake district-wide planning and to facilitate capacity building), located in southern Gauteng (Burger 2011). The metals, energy and construction sectors dominate the economy of the area, but also include some agricultural activities, and a large tourism and leisure component as the Vaal dam and Vaal river are located within the area. The geographical extent is $4173 \mathrm{~km}^{2}$, with an estimated population of 916484 people in 2011 (Statistics South Africa 2011).

A mixed method of research was used to gather data. Group 1 consisted of 14 officials, not in management positions, and Group 2 comprised 11 officials in senior management positions. A total of 38 managers were employed at the time of the study, thus equalling a sample size of 28 percent. Approximately 40 questionnaires were distributed to members of Group 1 but only 14 responded. There was a clear trend in the results from Group 1 and the participants came from various departments within the municipality. Group 1 were provided with a questionnaire by email. Group 2 (management, including the chief financial officer, heads of departments and other senior managers/directors) were also provided with a similar questionnaire; in addition, one-on-one interviews were conducted with each participant to 
determine their personal views and perceptions on all the topics raised.

The questionnaire was designed by incorporating the guidelines of risk management as set out by the National Treasury Public Sector Risk Management Framework (South Africa 2010). The questionnaire comprised five sections that aimed at determining the knowledge and declared attitude of the respondents towards risk management. Closed and open-ended questions were used. Additional notes were taken during the personal interviews with respondents from Group 2. Participants answered the questions by means of indicating either 'yes', 'no' or 'unsure'.

\section{Findings}

The questionnaire survey highlighted several problems within the municipality regarding risk management. Some of these problems were also identified in 2011 within its Enterprise Risk Management Framework compiled by SDM Management. The problems include the following:

- compliance - risk management is seen only as compliance with policy and not considered important on an operational level;

- lack of support - there appears to be inadequate support from senior risk management units such as the chief risk officer, and/or risk committees;

- a silo approach - risk management is being practised on an individual level and not in terms of enterprise risk management;

- discouraging perception - there is a perception that risk management will create more work for employees. If risk management is conducted properly, it can actually reduce workloads; and

- lack of knowledge - there is a clear lack of knowledge regarding risk management requirements (Sedibeng District Municipality 2011).

For the purpose of this paper, the individual questions and responses were not analysed separately. Only the questions yielding a high 'no' response were analysed, as well as the combined averages of each section. The combined results for the five sections were compared between the two groups to determine if there was a difference on how risk is managed and perceived, as well as the skills and knowledge of risk between management and non-management employees.

Table 1: Comparisons of average responses between Group 1 and 2

\begin{tabular}{l|c|c|c|c}
\hline \multirow{2}{*}{ Section } & \multirow{2}{*}{ Group* } & \multicolumn{3}{c}{ Response (\%) } \\
\cline { 3 - 5 } & & Yes & Unsure & No \\
\hline \multirow{2}{*}{ 1.General risk management } & Group 1 & 53 & 30 & 17 \\
\cline { 2 - 5 } & Group 2 & 56 & 11 & 36 \\
\hline \multirow{2}{*}{ 2. Risk identification } & Group 1 & 29 & 34 & 37 \\
\hline \multirow{2}{*}{ 3. Assessing risk } & Group 2 & 70 & 0 & 30 \\
\hline \multirow{2}{*}{ 4. Risk response } & Group 1 & 24 & 52 & 24 \\
\cline { 2 - 5 } & Group 2 & 82 & 0 & 18 \\
\hline \multirow{2}{*}{ 5. Monitoring of risk } & Group 1 & 37 & 58 & 5 \\
\cline { 2 - 5 } & Group 2 & 86 & 3 & 11 \\
\hline
\end{tabular}

* Group $1(n=14)$, non-management employees; Group $2(n=11)$, management officials.

Throughout all five sections of the questionnaire, it was evident that in many cases Group 1 was 'unsure' about the meaning of the questions. This could mean that they were either too timid or ashamed to admit that they did not understand the significance of the topic. In most cases, it could be assumed that they were uninformed of how risk management procedures work within the municipality. Group 2 rarely replied 'unsure' to the questions, as they appeared to have a broader understanding of risk management and what is required from them as managers to maintain and manage risk at an acceptable level. In many instances, there was only a limited negative response to some of the questions. The specific questions yielding a high 'no' response are discussed below. 


\subsection{Section 1: General risk management analysis}

This section of the questionnaire, which posed 12 questions, aimed at determining the level of general risk knowledge possessed by respondents.

Some of the questions that raised possible problems were: 1) Do you have a chief risk officer (CRO) and staff with necessary skills and competencies to manage risk within the SDM? In Group 1, only 57 percent replied 'yes', meaning that 43 percent were either 'unsure' or did not know; 54 percent of Group 2 replied 'yes'. At the time of conducting the interviews and distributing the questionnaires, the SDM had not appointed a CRO. Question 2) Does the risk manager or delegated authority often have meetings with your department? A remarkable 86 percent of Group 1 and 82 percent of Group 2 responded 'no'.

According to the PSRMF, an enabling environment for managing risk should be created. This should be done by following some of the basic guidelines as set out in the framework. Some of these guidelines require that adequate human resource capacity with the right skills should be provided; internal processes must be established to make employees aware of risk management; training and support should be provided to everyone involved in risk management; the CRO and his/her staff should have appropriate competencies and skills to execute risk management (South Africa 2010:21-25).

Non-management officials (Group 1) were unsure about some of the terms used and questions asked. This could be due to lack of knowledge or understanding of the topic. The officials in management positions (Group 2) were more informed regarding general risk management. Clearly, additional training and workshops should be held to inform employees of risk management more fully. Many employees were not aware that risk management activities had to be performed.

\subsection{Section 2: Risk identification activities}

This section of the questionnaire aimed at determining the level of risk identification activities the study population implement within their departments.

Some of the questions that raised possible concerns were: 1) Does your department have a comprehensive inventory of risks that might prevent, degrade, delay or enhance the achievement of objectives? Only 27 percent of senior management staff replied 'no'; 86 percent of Group 1 respondents did not know or replied 'no'. Question 2) Is the risk identification an ongoing process to identify new and emerging risks timeously within your department? Almost half of Group 2 replied 'no' and as many as 86 percent of Group 1 respondents were either unsure or also answered 'no'. Question 3) Does your department hold risk workshops and interviews to identify, filter and screen risks? 93 percent of Group 1 and 82 percent of Group 2 respondents replied 'no'.

According to the PSRMF, risk identification should include generating a comprehensive risk inventory list, such as a risk register. The SDM does have such registers in place, although a large number of the management and nonmanagement employees were not aware of the existence of these lists. Furthermore, risk identification should be an ongoing process and workshops and interviews can be used as useful tools for identifying risks (South Africa 2010:3031).

Group 1 was unsure about some of the terms and questions asked in this section regarding risk identification. They also replied 'no' to many of the questions, implying that efficient identification methods are not in place. Group 2 is mostly aware of risk identification processes; however, their knowledge and understanding can be improved by means of better training. Once again, certain critical issues regarding risk management were not in place.

\subsection{Section 3: Risk assessment activities}

This section aimed at determining the extent of risk assessment activities respondents implement within their departments. Risk assesment can be defined as the process of systematically quantifying or qualifying the level of risk associated with a specific event (South Africa 2010:34). Four questions were posed to Group 2 and three to Group 1 participants. It was clear that members of Group 1 did not understand the questions as most responses indicated either 'unsure' or 'no'. Group 2 assesses risks to an acceptable level, although 36 percent replied that they did not regularly reassess risks to ascertain the shift in magnitude of the risk in order to adjust the management action required. Other questions asked in this section included: 1) Does your department undertake risk assessment to determine the level of risk? and 2) Does your department prioritise the most important risks?

The PSRMF clearly states that risks should be prioritised and that the level of risk should be determined and 
monitored in order to adjust the response when necessary. With proper risk management in place, assessing risk should not be difficult to uphold. Generally, Group 1 participants were not familiar with this process. Group 2 implements risk assessment, to a large extent, within their respective departments.

\subsection{Section 4: Risk response activities}

In this respect the questionnaire sought to determine the magnitude of risk response activities respondents implement within their departments. The term risk response can be defined as the process of developing strategies to reduce or eliminate situations that create risk (South Africa 2010:36). A total of nine (Group 1), and ten (Group 2) questions formed part of this section. Once again, there was a clear lack of understanding and knowledge in Group 1, as most of the responses were 'unsure'. However, only 5 percent of combined responses were 'no'. This could indicate that Group 1 either agreed with the question, meaning that they implemented what was being asked, or they did not know. Few replied that the actions referred to in the questions were not executed. In Group 2, most of the respondents agreed that the correct procedures were followed.

Some of the questions that raised possible concerns in Group 2 were: 1) Do you have a range of options on how to mitigate and resolve identified risks? 36 percent replied 'no' and 9 percent were 'unsure'. 2) Does your department have a strategy to reduce or eliminate the threats and events that create risks? Only 73 percent replied 'yes'.

The PSRMF specifies that responding to risk will involve evaluating and identifying a possible range of options in order to mitigate risks. It further states that response strategies should be designed. These can include strategies such as avoidance, transferring, acceptance, and exploiting of risks. In the analysis, it can be seen that within Group 1 proper risk response methods are not in place, whereas Group 2 is implementing effective risk response procedures.

\subsection{Section 5: Risk monitoring activities}

Here the questionnaire sought to determine the extent of risk monitoring that respondents implement within their departments. Risk monitoring means checking regularly if the risk management system is functioning properly. Some questions asked in this section included: 1) Do you perform regular risk monitoring in your department and if yes, how often? Do your monitoring activities focus on determining whether or not the allocated responsibilities are being executed effectively, and are response strategies producing the desired result of mitigating risks?

According to the PSRMF, monitoring risks should be an ongoing process by means of determining if responsibilities are being executed and if strategies are providing the required results.

As many as 27 percent of Group 2 respondents replied that regular monitoring of risks was not taking place. Most of the Group 1 responses were 'unsure', once again indicating that they do not understand the contents of this section. Group 2 performed proper monitoring activities.

The overall outcome of the combined analysis indicated that Group 2 had more knowledge regarding the risk management procedures than Group 1. It also revealed that in some cases, proper management procedures were not followed but in others, they were in place.

\section{Conclusion}

Risk management is a broad term that can cover many kinds of practices. Within the public sector, one of the most important aspects of risk management is asset and revenue management. Without proper risk management, major financial losses can be incurred. This study indicates that, up to the date of this study, some aspects of risk management are absent within the Sedibeng District Municipality. This was already identified in the 2011 Enterprise Risk Management Framework compiled by the management of Sedibeng as well as by the Auditor General, who highlighted in his 2011 financial audit report on the municipality that there was a lack of appropriate risk management.

This study shows that the Sedibeng District Municipality lacks a centralised trained risk management unit. Little or no workshops/training regarding risk management is provided. The knowledge and skills regarding risk management for non-management employees are relatively limited and should be improved. It appears that proper policies, guidelines and frameworks are in place within the SDM, yet the contents and prescriptions of these documents are not applied effectively by the management and working activities of employees. Based on the outcome of the study, as well as incorporating the analysis of the PSRMF, it is recommended that a CRO should be appointed, regular risk workshops and training for management and officials should be held, and risk champions should be identified within all departments to distribute the risk management strategy among all staff members and encourage a positive risk culture within the various departments. 
Although it is important that risk management should be practised as part of municipal compliance, it should also form part of all managers' duties. The culture within the municipality should be changed to encourage an enabling environment for risk management.

The financial and practical implications that risks pose to the management process of public institutions should require top management, line managers and staff functionaries in the public sector to invest time and effort into the establishment of a proper risk management system.

\section{References}

AGSA (Auditor General of South Africa). (2011). Auditor's report of the auditor-general to the Gauteng Provincial legislature and the council of the Sedibeng District Municipality. Pretoria: AGSA.

AGSA (Auditor General of South Africa). (2012). Auditor's report of the auditor-general to the Gauteng Provincial legislature and the council of the Sedibeng District Municipality. Pretoria: AGSA.

Burger, D. (2011). Government communication and information system. South Africa Yearbook 2011/2012. [Online] Available: http://info.gov.za/aboutgovt/locgovt/categories. (March 14, 2013).

Cameron, R. (1999). Democratisation of South African Local Government. A Tale of Three Cities. Western Cape: Van Schaik.

Cleary, S.M. and Malleret, T.D. (2006). Resilience to risk. Business success in turbulent times. Paarl: Human \& Rousseau.

Correia, C., Flynn, D., Uliana, E. and Wormald, M. (2003). Financial management. $5^{\text {th }}$ ed. Paarl: Juta.

Crockford, N. (1986). An introduction to risk management. $2^{\text {nd }}$ ed. Cambridge, UK: Woodhead-Faulkner.

Frigo, M.I. and Anderson, R.J. (2011). Strategic management: What is strategic management? [Online] Available: http://www.markfrigo.com/What_is_Strategic_Risk. (March 6, 2013).

Garret, B. (2003). Thin on top: Why corporate governance matters and how to measure, manage, and improve board performance. London: Nicholas Brealy.

Jobst, A.A. (2007). Constraint of consistent operational risk measurement and regulation. Journal of Operational Risk, 5(2), 10-15.

Kenosi, R. (2007). Certificate programme in management development for municipal finance. Managing risk in a municipal context. Wits Business School, University of the Witwatersrand.

Manuli, D. (2012). Sedibeng District Municipality: external communications media release. Vaal 21.

Republic of South Africa. (2003). Local Government Municipal Finance Management Act (56 of 2003). Pretoria: Government Printer.

Republic of South Africa. (1996). Constitution of the Republic of South Africa (Act 108 of 1996) as adopted by the Constitutional Assembly on 8 May 1996. Pretoria: Government Printer.

Republic of South Africa. (1999). The Public Finance Management Act (1 of 1999). Pretoria: Government Printer.

Republic of South Africa. National Treasury Department. (2010). Public Sector Risk Management Framework. [Online] Available: http://oag.treasury.gov.za/psrmf.asp. (January 10, 2013).

Rossouw, D. and Van Vuuren, L. (2010). Business Ethics. $4^{\text {th }}$ ed. Cape Town: Oxford University Press.

Sedibeng District Municipality (South Africa). (2011). Enterprise Risk Management Framework.

Spaulding, W.C. (2005). Handling risk, avoidance, loss control and retention. [Online] Available: http://thismatter.com/money linsurance/handling-risk.htm. (April 27, 2013).

Statistics South Africa. (2011). Municipal Fact Sheet. Pretoria: Statistics South Africa.

The Local Government Handbook. (2013). a Complete Guide to Municipalities in South Africa. [Online] Available: http://www.localgovernment.co.za/south-africa/district-municipality/14. (February 7, 2013).

The Presidency. (2012). Management Performance Assessment Tool 2011/12 report. [Online] Available: http://www.thepresidency.gov.za. (November 13, 2013).

Turnbull Report. (2005). Revised guidance for directors on the combined code. London: The Financial Reporting Council.

Umdoni Local Municipality. (2011). Umdoni Local Municipality Integrated Development Plan (IDP).

Van Niekerk, T. (2012). Local government turnaround strategy. Challenges, constraints and benefits. Administratio Publica, 20(2):66

Visser, C.B. and Erasmus, P.W. (2009). The management of public finance. Cape Town: Oxford University Press.

Weller, N. (2008). Strategic and operational risks. [Online] Available: http://www2.accaglobal.com/ document/risk (March 7, 2013). 